\title{
MIGRAÇÕES INTERNACIONAIS COMO OPORTUNIDADE INTERCULTURAL: DESAFIOS E CONTRIBUIÇÕES PASTORAIS NA PERSPECTIVA DA INTERCULTURALIDADE
}

\author{
International Migration as an Opportunity for Interculturality: Pastoral \\ Contributions and Challenges in Intercultural Perspective
}

Carmem Lussi *

\begin{abstract}
"As culturas são formas de vida e modos diferentes de ver e viver a realidade. Por isso, eu considero que a interculturalidade é o imperativo histórico e cultural mais importante que existe, para a sobrevivência de nossa humanidade". (PANIKKAR, 2009, p. 238)
\end{abstract}

RESUMO: A governância e o estudo das migrações internacionais desafiam estudiosos(as) do tema, agentes que atuam com migrantes e refugiados, os próprios sujeitos em mobilidade e, especialmente, lideranças de instituições que fazem interface com os fenômenos relacionados aos deslocamentos populacionais. As situações consideradas emergências migratórias se multiplicam, enquanto são ainda escassos os esforços por uma compreensão das migrações como fenômeno estrutural da humanidade e oportunidade para os povos e para os sujeitos que integram os fluxos. Este artigo é uma tentativa de reflexão teológica e pastoral, inspirada na interculturalidade como categoria para a leitura e a análise dos desafios e das possibilidades que as migrações internacionais oferecerem e demandam de seus atores, a partir de alguns textos de Raimon Panikkar (1918-2010). O autor compreende a interculturalidade como pensamento e como práxis que incide na qualidade da convivência entre pessoas de culturas e religiões diferentes.

PALAVRAS-CHAVE: Migrações. Interculturalidade. Raimon Panikkar. Pastoral migratória. Desafios pastorais.

ABSTRACT: The governance and the studies on international migration challenge scholars of the issue, agents working with migrants and refugees, the subjects

* Centro Scalabriniano de Estudos Migratórios - CSEM, Distrito Federal, Brasília, Brasil. 
on the move themselves and, especially, leaders of institutions that interface with the phenomena related to people on the move. The situations considered as migratory emergencies multiply, while efforts to understand migrations as a structural phenomenon of humanity and an opportunity for the peoples and the individuals who integrate the flows are still scarce. This article is an attempt of a theological and pastoral reflection, inspired by interculturality as a category for reading and analyzing the challenges and possibilities that international migrations offer and demand from their actors. Based on some texts by Raimon Panikkar (1918-2010), interculturality is understood as a thought and as a praxis that focuses on the quality of coexistence between people of different cultures and religions.

KEYWORDS: Migration. Interculture. Raimon Panikkar. Pastoral Care for Migrants. Pastoral Challenges.

\section{Introdução}

$\mathrm{D}_{\mathrm{t}}$ urante a palestra realizada dia 04 de outubro de 2018, em Belo Horizonte, no Simpósio Internacional "Diálogos inter-religioso e intercultural, no centenário de Raimon Panikkar"1 Raul Fornet-Betancourt argumentou que a migração é um lugar sagrado, porque é lugar de encontro com Deus e porque Deus e o humano se encontrando é algo sagrado, por isso terra de migração é terra abençoada.

Em sua reflexão, o filósofo cubano defendeu a importância do pensamento como ação e compromisso; "a filosofia tem que ser compromisso e ação", afirmou, e a primeira entre as ações comprometidas que apontou é a de acompanhar as lutas dos grupos e das pessoas que tentam recuperar ou criar tempos e espaços de seus ritmos de vida que não sejam simplesmente margens concedidas pelo capital e seus mercantes. Segundo ele, trata-se de reconhecer vida, contextos, afetos que são processos de diálogo e de compromisso e que promovem lugares para a diversidade, resgatando todos os espaços possíveis à humanidade, à vida com dignidade para todos e todas.

Assim, Fornet-Betancourt introduz a interculturalidade como uma postura específica a ser assumida pessoalmente, o que implica que a pessoa se situa estrategicamente de modo a se habilitar para sustentar processos de criatividade e libertação, na busca por objetivos comuns de vida digna e de direitos humanos, que sejam respeitados para todos e todas. Essa perspectiva abre para leituras e para práxis desafiadoras sobre a

\footnotetext{
1 Mais informações sobre o referido Simpósio podem ser encontradas em <https://www. faculdadejesuita.edu.br/eventodinamico/eventos/index.php?pagina=grupo_conteudo\&tela=3 5\&usuarioparoquia=\&subtela=\&evento=51>. Acesso em: 11 mar. 2019.
} 
temática migratória, que vão muito além da curta visão das abordagens emergenciais ao tema, prevalentes no contexto brasileiro. Referindo-se a Raimon Panikkar, ele sustenta que a interculturalidade deve ser entendida como atitude pessoal e como estratégia de uma visão diferenciada da convivência humana.

A interculturalidade pode viabilizar uma interpretação das migrações e de outras alteridades da convivência humana a partir de relações interpessoais contextualizadas, onde o amor faz parte do tecido no qual as diversidades entram em relação. Sem interculturalidade, a abordagem da temática migratória facilmente se deixa determinar pelo medo das diferenças, que transforma a alteridade em desigualdades. Estas, por sua vez, podem se tornar ameaças para a dignidade de pessoas e grupos migrantes e refugiados, pela diversidade que os caracteriza.

Organizei as reflexões que convergiram neste texto, que faz eco às contribuições da teologia intercultural, e especialmente aos inputs dos estudos de Raimon Panikkar, em quatro partes. Depois de uma introdução sobre critérios do olhar para a realidade migratória, segue breve apresentação do conceito de interculturalidade como pensamento e como práxis. Em seguida proponho algumas declinações da abordagem intercultural à mobilidade humana relativamente a processos humanos, sociais e culturais nos quais migrantes e refugiados ${ }^{2}$ buscam reconstruir suas vidas em terra estrangeira. A seguir, indico alguns percursos interculturais e como conclusão aponto questões pastorais que a presença de sujeitos migrantes ou refugiados pode promover em contextos locais ou nacionais.

\section{Visões da realidade}

Uma abordagem intercultural ao tema da mobilidade humana internacional demanda que a leitura interpretativa dos fenômenos relativos à imigração e ao refúgio não se reduza a dados estatísticos e à gestão emergencial das situações de risco relacionadas aos fluxos de mobilidade humana. Atenção a sujeitos em condições de risco e tensões sociais por fenômenos que podem ser identificados como 'emergências migratórias' existem e precisam ser gerenciadas em sua especificidade, com a urgência e o necessário profissionalismo que os fatos requerem. Mas reduzir a visão e a atuação ao momento emergencial não rende justiça aos sujeitos nem à história.

${ }^{2}$ Com a expressão geral 'migrações e refúgio', entendo incluir aqui as mais diversas modalidades e motivações do migrar, sem simplificar a ampla variedade de perfis de sujeitos e situações que provocam e caracterizam os fluxos migratórios. 
O pensamento intercultural auxilia a superar a cegueira que uma abordagem superficialmente casuística e conjuntural, baseada em fatos contingentes e emergenciais tende a favorecer, o que faz avançar processos interativos no sentido apontado pelo Papa Francisco de uma cultura do encontro (2016) e prevenir a formação de conflitos e a falta de coesão social e eclesial, assim como atitudes e linguagens racistas em contextos de imigração. Segundo Panikkar, as tensões que contrapõem as culturas e "a vitória de uma cultura sobre outra nunca conduziu à paz" (2009, p. 292).

Segundo o pensador, místico e filósofo indo-espanhol, "a interculturalidade é o imperativo histórico e cultural mais importante que existe, para a sobrevivência de nossa humanidade" (PANIKKAR, 2009, p. 238). As migrações fazem com que se encontrem pessoas que são portadoras de culturas, de formas de vida e modos diferentes de ver e viver a realidade. Tais elementos de diversidade aguçam a percepção distorcida pelo medo e eventuais interesses de manipular as diferenças que as sociedades desenvolvem em seus processos sociais e culturais, políticos e religiosos. Essas reações acontecem sobretudo entre pessoas que nunca emigraram de seu país de origem e que tendem a ser decididamente autorreferenciais em suas percepções do real.

Se, por um lado, "os modos através dos quais as sociedades 'constroem' as diferenças mudam no tempo e no espaço" (ZANFRINI, 2011, p. 2), por outro, - enquanto as migrações se tornam cada vez mais espelho dos desafios da crescente visibilidade das diferenças na esfera pública - emergem as consequências do trato discriminatório e parcial que tendencialmente é reservado aos sujeitos em situação de mobilidade pelos gestores da coisa pública e pelos líderes institucionais. Segundo Zanfrini, "as diferenças designam as características dos sujeitos; enquanto que as desigualdades indicam o acesso diferenciado a certos recursos e oportunidades" (2011, p. $X)$. No contexto eclesial não é diferente, pois as relações interpessoais na comunidade cristã são permeadas transversalmente pelo que as pessoas e os grupos vivem e pelas características de que são marcadas as realidades sociais e culturais.

Os problemas provocados ou agravados pelos fluxos migratórios onde faltam condições de vida e segurança, provocam ou favorecem os discursos que criminalizam as migrações e discriminam/rejeitam seus sujeitos. Por mais que leis e políticas tentem impedir os deslocamentos populacionais limitando, impedindo ou dificultando a entrada nos países escolhidos como territórios de destino por migrantes e solicitantes de proteção internacional, segundo o estudioso de migrações Douglas Massey, "as tentativas de suprimir os fluxos populacionais que são uma consequência natural da participação dos países nas redes econômicas não terão sucesso; em vez disso, eles apresentarão sérias ameaças aos direitos individuais, às liberdades civis e à dignidade humana" (MASSEY, 2017, p. 183). 
Igrejas, governos e sociedade civil insistem no apelo à solidariedade e na denúncia de violações de direitos de migrantes e refugiados. Muitos são os esforços logísticos, programáticos e mentais para pensar e prever a convivência que o ingresso de pessoas de outras nacionalidades, culturas, idiomas e religiões fazem acontecer nos locais de trânsito e de destino dos fluxos migratórios. Com o tempo, emerge a importância de cuidar também dos processos socioculturais a médio e longo prazo, onde a abordagem intercultural contribui sobremaneira para o êxito final.

A interculturalidade coloca a cada um de nós um interrogativo (termo que prefiro a 'desafio') sobre nosso modo de viver, sobre nossa visão da realidade e sobre nosso modo de pensar [porque cada] cultura não é um modo de ver o mundo: cada cultura é um mundo; não é uma visão do mundo e sobre o mundo: cada cultura nos apresenta (e não só representa) um mundo no qual vivemos realmente (PANIKKAR, 2009, p. 192-193).

O desafio intercultural rompe com o segmento unidirecional nós-eles, para que também migrantes, dissidentes, gênios ou qualquer categoria de sujeitos considerados diferentes já não sejam culturalmente considerados desiguais por sua singularidade. A interculturalidade faz com que sejam reconhecidos como atores ativos e criativos na construção de convivências plurais e de um tipo de coesão que não massifica. E, igualmente, promove processos novos, em que a insegurança não representa ameaça e em que o diálogo (PANIKKAR, 2009, p. 250-251) acontece como "encontro e descoberta da possibilidade de influência recíproca" (PANIKKAR, 2009, p. 255). Uma reciprocidade que enriquece e pode também desestabilizar. De fato, na visão de Panikkar, a "interculturalidade nos tira a certeza absoluta, mas nos fortalece na confiança nos outros e, portanto, também em nós mesmos" (2009, p. 303).

\section{Interculturalidade como pensamento e práxis}

Apesar da dificuldade de realizar a tarefa, faz-se necessário tentar formular alguns parágrafos para explicar um pouco a compreensão do que é a interculturalidade.

Com María Pilar Aquino, pode-se afirmar que

o significado do conceito de interculturalidade não pode ser encapsulado em definições fechadas, uma vez que são as próprias pessoas os atores e os sujeitos do processo intercultural. As pessoas [concretas], portanto, entram [nessa] dinâmica de transformação [que é a interculturalidade] como agentes participantes que interagem a partir de diferentes culturas e como sujeitos portadores de agendas de mudança (2007, p. 14). 
A reflexão de Pilar Aquino se configura como uma análise da intuição de Panikkar, elaborada em linguagem e com atenção às vivências femininas, ligadas à vida, onde a especificidade do gênero feminino, seus sofrimentos e seus aportes são amalgamados através de uma interpretação existencial que elaboram as teorias e a espiritualidade em cotidianos transformadores, unindo pensamento e práxis em movimentos inseparáveis.

A teóloga mexicana abraça a perspectiva intercultural da herança de Raimon Panikkar, que contém registros de algumas formulações elaboradas nas experiências vividas por ele através do encontro intercultural ${ }^{3}$.

O primeiro e principal elemento que explica a interculturalidade, segundo Panikkar, é sua dimensão profundamente existencial relacionada com os sujeitos atores dos processos relativos à dinamicidade dos encontros e desencontros entre pessoas de culturas diferentes. A interculturalidade é atitude e significado, da identidade e da linguagem, das relações e das escolhas, que penetra todas as dimensões interativas das realidades humanas, onde a diferença da cultura, da mentalidade, da religião das pessoas e dos povos entram em relação em processos positivos e construtivos, sem negar as alteridades. Para Panikkar são os deslocamentos populacionais que caracterizam a oportunidade intercultural por excelência.

Sua afirmação se refere especificamente ao diálogo, que para Panikkar não é uma forma ou expressão de interculturalidade, mas um evento intercultural em si mesmo. "O diálogo que nos interessa é algo mais do que o diálogo com o vizinho. /.../ O diálogo intercultural no sentido próprio do termo tem lugar com o estrangeiro, o imigrante, o refugiado" (PANIKKAR, 2006, p. 23). Segundo ele, o diálogo é sempre "vulnerável", não pode excluir a subjetividade de cada participante (2006, p. 45). Assim, na igreja como na sociedade, a interculturalidade não é um programa que pode estabelecer metas e percursos previsíveis, é uma mentalidade e a qualidade de processos complexos, imprevisíveis e ao mesmo tempo promissores.

\footnotetext{
${ }^{3}$ As referências privilegiam os textos de Raimon Panikkar por reconhecimento de sua grandeza e profundidade sobre o tema. Registro, para eventuais leitores que tiverem interesse, que existem outras correntes de pensamento sobre interculturalidade, especialmente em contexto teológico/missiológico, que merecem destaque, como por exemplo a Teologia Intercultural de matriz alemã. A "teologia intercultural/missiologia deve ser descrita como uma disciplina teológica que reflete (1) a relação entre o cristianismo e as religiões e visões de mundo não cristãs e (2) a relação entre o cristianismo ocidental e suas variantes culturais não ocidentais. /.../ À teologia intercultural interessa, portanto, em primeiro lugar, uma percepção diferenciada de formas de fé e de reflexão sobre elas" (VON SINNER, 2012, p. 47-48 - Cf. nota de rodapé da p. 47 onde há referências históricas). Cf. também ESSEN, 2007, p. 283-293.
} 
Se por um lado há uma visão positiva, que assegura resultados humanos e culturalmente desejáveis na lógica da dignidade humana, da coesão social e da comunhão eclesial, com Panikkar cabe ressaltar que a "interculturalidade desestabiliza ideias e convicções enraizadas muitas vezes no mais profundo das culturas" (2006, p. 14). Isso explica a dificuldade e muitas resistências para a compreensão e a adoção da abordagem intercultural.

A interculturalidade não é uma estratégia, nem uma metodologia ou um modus operandi a ser aprendido para qualificar e facilitar a comunicação e a interação entre pessoas de diferentes backgrounds. A atitude intercultural é um processo intrínseco ao desenvolvimento e à interação que implica a dimensão dos valores que atribuem significados à vida de uma pessoa e sua própria identidade. Por isso "implica em riscos e traz consigo a aceitação da vulnerabilidade humana" (PANIKKAR, 2006, p. 87). A interculturalidade "revela nossos limites, nos ensina a tolerância e nos faz compreender a contingência da condição humana" (PANIKKAR, 2006, p. 71).

Em sua dimensão de práxis, a interculturalidade estabelece interpelações que Panikkar formula em termos de qualidades do ser. As principais podem ser assim sintetizadas: a) a atitude de abertura às diferentes culturas; b) a disponibilidade ao diálogo dialogal no qual as pessoas se educam reciprocamente, ao invés de interesse em educar à interculturalidade; c) a compreensão que todo ser humano é um mistério e que só amando-o é possível conhecê-lo; d) o desenvolvimento da arte e da ciência da escuta, para escutar efetivamente o outro e entender o que a outra pessoa diz de si mesma; d) a capacidade de visão sobre as deficiências do próprio sistema cultural antes de observar as deficiências dos sistemas culturais dos outros; e) o processo de libertação do primado da razão (cf. PANIKKAR, 2009, p. 202-222).

\section{Interpretações interculturais}

A experiência existencial migratória desencadeia nas vias das migrações processos humanos e socioculturais de desenvolvimento de uma abertura paradigmática, mental e emocional, ao outro, que quem não foi migrante/ refugiado pode não conhecer e que Pannikar elabora em termos interculturais. "A abertura ao outro nasce da experiência de nossa contingência, porque somente quando superamos a convicção que somos autossuficientes reconhecemos o outro como sujeito, como uma fonte de conhecimento e de amor, e não somente como um objeto de nossa busca" (PANIKKAR, 2006, p. 121). 
Assim como a transformação radical que a migração pode forjar, outros fenômenos relacionados com a mobilidade humana podem ser reconhecidos e interpretados positivamente como processos interculturais. $\mathrm{Na}$ sociedade em geral, na Igreja, no conhecimento ou na comunicação, a interculturalidade e os deslocamentos populacionais reafirmam e favorecem a oportunidade de acreditar que outro mundo é possível, que um mundo melhor é possível.

Indico a seguir quatro declinações sobre como pode se configurar, concretamente, a interculturalidade, com base na visão de Raimon Panikar.

A dignidade e o reconhecimento do valor imprescindível e inalienável do ser humano. Esta é a primeira consequência da adoção da interculturalidade como parâmetro e atitude, desde a abordagem direta até a análise política das alteridades que interferem na convivência humana, com ou sem a presença de migrantes e refugiados. A presença destes vem a reforçar a oportunidade. "Quando falamos da interculturalidade estamos falando diretamente da confiança no outro, no outro que não pensa como eu, porém é, como eu, um ser humano. Não existe árbitro, porque o arbítrio não pode ser a minha razão nem a do outro. Precisamos dialogar" (PANIKKAR, 2009, p. 220).

A referência constante da interculturalidade ao diálogo acompanha a emergência de conflitos em contextos de convivência de diferentes culturas. A contribuição de Pannikar sublinha que "a interculturalidade, antes de ser uma relação entre culturas, é um encontro entre pessoas. O homem fala para entender os outros e para entender melhor a si mesmo, mas também para ser entendido pelos outros" (PANIKKAR, 2009, p. 272).

Conjuntamente ao reconhecimento e à proteção da dignidade e da alteridade, a interculturalidade se faz promotora de uma cultura da paz que aceita e até promove modelos diferentes e até divergentes de sociedades plurais, não nega nem foge dos conflitos e constrói a consolidação das relações em comunidades sem padronizar pensamentos e atitudes, perfis ou funções.

O caminho se faz concreto no perdão, porque a existência de conflitos faz parte da interação humana. "Aprendi nos campos de refugiados que só o perdão traz a paz e estou convencido que quem perdeu tudo pode trazer esta paz a quem tem o privilégio de poder escutar - mesmo sem viver diretamente - a dor da humanidade" (PANIKKAR, 2006, p. 97). A intercultura penetra, assim, no coração da boa nova do Reino, em que o amor a Deus não se distingue do amor ao próximo, o qual se dá unicamente onde o perdão se renova ao infinito.

Uma reflexão muito próxima à visão de Panikkar sobre a convivência humana intercultural foi elaborada por Marcela Lagarde y De Los Rios em 
reflexão sobre a sororidade entre mulheres, que cito pela eloquência de sua expressão para o tema aqui tratado. Aprender a interculturalidade é como, para uma mulher, aprender a ser irmã/mana de tantas outras; pois a sororidade "es una experiencia de las mujeres que conduce a la búsqueda de relaciones positivas y la alianza existencial y política, cuerpo a cuerpo, subjetividad a subjetividad con otras mujeres, para contribuir con acciones específicas a la eliminación social de todas las formas de opresión y al apoyo mutuo para lograr el poderío genérico de todas y al empoderamiento vital de cada mujer" (2012, p. 560).

Intercultura e solidariedade entre migrantes e refugiados, para resistir à discriminação e para avançar em projetos de empoderamento e de resistência.

A promoção de processos de transformação para a construção de sociedades inclusivas e a consolidação da justiça. Para Panikkar, o mundo precisa entender que na falta da interculturalidade entre as pessoas de culturas diferentes, existe a guerra. Sua interpretação dos fenômenos relacionados com o encontro de povos de culturas diferentes é experiencial; seus textos e suas posturas são autobiográficos, apesar de assumirem, com o tempo, formulação mística e filosófica. Ele explicita a consciência de que "nossa abertura à interculturalidade nos obriga a renunciar ao ideal de uma realidade completamente inteligível" (PANIKKAR, 2009, p. 285) e a confiar no ser humano. "Sem confiança nas outras culturas... a interculturalidade degenera em multiculturalismo, que é uma estratégia, fundamentalmente inconsciente, para absorver outras visões do mundo e perpetuar assim a síndrome da ideologia da cultura superior" (PANIKKAR, 2006, p. 106).

A extraordinária novidade e a radicalidade da análise da realidade contemporânea, em Panikkar, relaciona a interculturalidade com sua fé e com sua confiança que é possível construir um modelo alternativo de governo, de relações, de sociedade e, certamente, também de igreja, não sem dificuldades.

A abertura à interculturalidade é verdadeiramente subversiva, porque desestabiliza, contesta convicções profundamente enraizadas que damos por óbvias porque nunca foram colocadas em discussão; é enriquecedora porque nos permite crescer, ser transformados, nos estimula a nos tornarmos mais críticos, menos absolutistas e amplia nosso campo de tolerância; e é difícil, porque é difícil o encontro de culturas, que nos convida a ser prudentes e realistas (PANIKKAR, 2006, p. 90-91).

Na labuta e na resistência à cultura hegemônica de quem acredita e aposta em percursos e metas interculturais, dão sua contribuição as vozes, os passos, as ideias e as experiências dos sujeitos que migram ou buscam refúgio em terras estrangeiras. A estas se unem as expressões e os esforços de homens e mulheres que participam dos mesmos processos 
pela fé que professam ou pelo amor que colocam em sua qualidade de vida e de relações interpessoais e profissionais, apesar de não migrarem. Estes podem incidir em seus contextos, mesmo onde uma mentalidade intercultural inicia por gestos e escolhas que acontecem através de fatos pequenos e fragmentados.

Uma nova construção na metodologia e até nos conteúdos da teologia, marcados pela transformação intercultural. Uma das oportunidades que a mobilidade humana favorece nos contextos eclesiais nas sociedades de destino de migrantes e refugiados é a transformação do modo de pensar a fé, porque a transmissão e a celebração da fé recebida e abraçada em outras culturas interpela e questiona os crentes de tradição consolidada em contexto monocultural. Trata-se da irrupção de uma nova consciência entre os cristãos que pensam sua fé, a consciência da culturalidade de cada expressão e reflexão teológica.

O teólogo austríaco Gmainer-Pranzl, a este respeito, se interroga sobre a "relevância que a identidade cultural das pessoas tem para a autocompreensão religiosa cristã" (2012, p. 3). Ele afirma que "a teologia intercultural leva a sério o lugar da experiência da fé, da reflexão a respeito da fé e da responsabilidade sobre ela e compreende-se, de certa maneira, como topologia da esperança cristã" (2012, p. 5). Assim, a interculturalidade em âmbito eclesial é uma tarefa em que a reflexão teológica se configura como

resposta a um envio que não pode ser realizado doutro modo a não ser de forma culturalmente plural. /.../ 'Interculturalidade' designa uma atitude epistêmica com a qual a teologia intercultural realiza a autodescrição da compreensão cristã da fé (GMAINER-PRANZL, 2012, p. 7).

Enquanto as migrações desafiam as relações para a intercultura, na Igreja a interculturalidade é dinamismo da fé e da vivência cristã, que influencia ações e pensamento.

A teologia intercultural /.../ [quer] ajudar a esclarecer e a compreender o que se coloca como pergunta, desafio e problema em uma comunidade de fé constituída mundial-eclesiasticamente; é a forma discursiva da catolicidade que concebe o Evangelho de Jesus Cristo não como posse de uma tradição cultural, mas como mensagem de salvação à 'família humana inteira' (GS 2) (GMAINER-PRANZL, 2012, p. 16).

Essa compreensão revela também como a mobilidade humana pode ser fermento que mobiliza as comunidades à reinvenção da fidelidade criativa à graça, que move os crentes a participar da salvação, sua e dos outros, do jeito da encarnação, isto é, do jeito de cada um e de cada uma, nas características e nos tons de suas identidades, que são sempre culturalmente configuradas.

\footnotetext{
${ }^{4}$ Tradução do original em alemão: Theologie interkulturell: die diskursive Form von Katholizität. Korrespondenzblatt des Canisianums, v. 143, n. 2, 2010, p. 16-34.
} 
Segundo-Fornet Betancourt, há também uma necessidade de transformação da religião pelo desafio intercultural, uma transformação inter-religiosa porque existe uma pluralidade de espiritualidades e de religiões que o exigem e, com os deslocamentos populacionais, estas diversidades se encontram, se cruzam e se interfecundam. Na compreensão do autor, a transformação religiosa é una necessidade para a teologia, pois isso vai "complementar su capacidad de hablar de Dios interculturalmente con el desarrollo de un lenguaje que libere su discurso sobre Dios de los límites de su religión de proveniencia por la interacción con el espíritu de Dios en el otro" (FORNET-BETANCOURT, 2017, p. 78). Ele considera que a transformação intercultural e inter-religiosa da teologia inicia quando acontece o esforço hermenêutico de pensar a própria tradição a partir da relação com o outro e da abertura a tradições religiosas e culturais 'outras'.

A interculturalidade marca, igualmente, uma atitude interior de não conformação ao status quo macroconjuntural, que veicula a ideia das migrações como um problema para os governos e uma ameaça ao bem-estar de poucos. Com o ato de migrar e as posturas de esperança, coragem e ousadia em insistir em projetos migratórios, migrantes e refugiados, interculturalmente, resistem ao monopólio do poder que se impõe através de políticas de criminalização das migrações, discursos racistas e leis antimigratórias.

\section{Para Fabrício Toledo de Souza,}

em paralelo à condição negativa dos movimentos de fuga, caracterizada pela recusa à violência, à fome e a privações, existe o desejo positivo de liberdade e democracia. $\mathrm{O}$ caráter ao mesmo tempo negativo e positivo da migração, a recusa e o desejo, apresenta uma força extraordinária, pois a fuga é uma forma de se produzir a resistência contra a opressão e a exploração do trabalho vivo (2014, p. 112).

Resistência e inconformismo caracterizam o ato próprio de migrar e, na visão intercultural, reafirma aquela vulnerabilidade das respostas seguras, dos movimentos certos e das seguranças que impedem a inclusão de pessoas, projetos e desafios novos nas interações e, portanto, nas instituições onde recursos e metas são definidos e disponibilizados.

Essa inconformidade inclui a discussão sobre a pluralidade religiosa, para além do medo do risco de relativismo religioso. A mobilidade humana é sentida em muitos contextos eclesiais como grave ameaça quando a referência à mobilidade humana aponta para a chegada de migrantes ou refugiados de outra tradição religiosa, especialmente se islâmica (MARINUCCI, 2015, p. 191s). Apesar da praxe eclesial, em quase todo o mundo, testemunhar a prioridade assegurada à acolhida e à interação com migrantes e refugiados, na perspectiva da interculturalidade, o reconhecimento da riqueza e a valorização da fé e da bagagem religiosa e cultura de outras tradições é sempre um desafio. Abordagens interculturais podem configurar uma pastoral integral e integrada, como "exigência que a ação eclesial 
(comunitária) seja configurada sempre em modo correto e eficaz, sob o perfil de sua postura social, histórica e cultural, assim como sob o perfil de sua qualidade evangélica" (SKODA, 2017, p. 6).

\section{Percursos interculturais promovidos pela mobilidade humana}

O pensamento e a práxis intercultural visam promover ações e reações, interação e esforços que representem e respondam aos desafios da construção de projetos ético-políticos para os povos e às exigências do respeito às alteridades que constituem o mundo em geral, e as comunidades locais, em específico. É nestas realidades que a vida humana se configura como tal ou é violada. Essa expectativa exprime radicalmente o que a interculturalidade significa quando a reflexão e os esforços se interrogam sobre a incidência do pensamento na atuação em decisões macroestruturais e, sobretudo, nas rotinas humanas e sociais que fazem de cada ser humano uma parte viva do tecido social, eclesial e político.

Nesse sentido, a chegada em um determinado território de pessoas novas que as migrações e a busca por refúgio trazem ao presente de muitos e muitas que nunca viveram residentes fora de seu micro contexto nacional, desencadeia reações e sentimentos, ações e omissões. Como a abordagem e os processos interculturais podem transformar sujeitos, relações e êxitos para migrantes, refugiados e também para autóctones, pessoas e comunidades que os recebem em seus contextos locais?

O desafio intercultural se refere às condições pelas quais o encontro entre diferentes culturas e religiões pode realizar o enriquecimento simbólico, teórico e prático de todos os atores. Sem receitas e sem tentar me eximir da tarefa de pensar percursos interculturais, indico algumas pistas, com ajuda de dois estudiosos que percorrem as vias da intercultura com fé e em diálogo intercultural há mais tempo. De fato, as categorias conceituais interculturais têm "a intenção de transformar a realidade e não simplesmente descrevê-la e explicá-la" (PILAR AQUINO, 2007, p. 22).

Por um lado, María Pilar Aquino, ecoando a Panikkar que enraíza a interculturalidade profundamente na existência e nas escolhas de cada pessoa, e citando Uma Narayan ${ }^{5}$, dá forma aos sentimentos que caracterizam uma visão intercultural em contexto eclesial. Ela exalta o papel feminino neste tipo de processo humano e religioso, e afirma que é tarefa das mulheres que creem e que pensam teologicamente

\footnotetext{
${ }^{5}$ A referência citada por Maria Pilar Aquino é: Uma Narayan. Dislocating Cultures: Identities, Traditions, and Third World Feminism. New York; London: Routledge, 1997. p. 37.
} 
abrir espaços dentro das instituições da sociedade, para que haja lugar para cada pessoa, especialmente para aquelas que são socialmente marginalizadas e impotentes, para que possam se tornar participantes ativas na articulação de seus interesses, compromissos e visões de justiça (PILAR AQUINO, 2007, p. 125).

Com ela, também aposto no poder da oportunidade, que faz de migrantes, refugiados e tantas mulheres e homens diferentes em contextos comunitários, sujeitos ativos, que só assumem seu papel se lideranças, instituições e sujeitos interculturais criam ocasião, abrindo espaços físicos e relacionais, dando crédito que gera responsabilidade compartilhada, assumindo o risco da solidariedade que sabe se colocar no lugar do outro empaticamente, para se retirar estrategicamente a fim de que a alteridade dê lugar à participação ativa.

A autora também ajuda a pensar a interculturalidade como desafio e oportunidade para a teologia porque

é uma nova racionalidade que expande o horizonte ético-político da teologia. /... / Segundo Ignacio Ellacuría, a preocupação central da teologia é tornar claro "quais atos históricos trazem a salvação e quais trazem condenação, que atos tornam Deus mais presente, e como essa presença é atualizada e efetivada neles em tais atos/eventos" (PILAR AQUINO, 2007, p. 13)

A interculturalidade em mentes e comunidades que pensam a fé cristã gera compromisso (LUSSI, 2015, p. 46-59), atuação libertadora, linguagens outras e, muitas vezes, sabe romper e dar forma e voz a temas e significados sobre os quais o silêncio eclesial produz um ruído ensurdecedor.

Por outro lado, Raúl Fornet-Betancourt sustenta que "a interculturalidade [deve ser] entendida como um 'tomar posição' pela vida" ou como um "modo de vida consciente em que uma postura ética em favor da convivência com as diferenças toma forma" (2004, p. 12-14), indicando o foco da incidência da interculturalidade em processos sociais e culturais. Para que isso aconteça, segundo Panikkar, é crucial a superação de modelos nos quais mentalidades e instituições, pessoas e projetos se estabilizam. Para ele "a interculturalidade nos intima não só e não tanto a mudar de paradigma, quanto a pensar sem paradigmas" (PANIKKAR, 2009 p. 219), o que significa de alguma forma a capacidade de romper com o que impede a construção de relações interculturais e a humildade de fazer escolhas na linha da vida e da qualidade evangélica da convivência humana.

${ }^{6}$ A referência é a Ignacio Ellacuría, The Historicity of Christian Salvation. In: ELLACURÍA, I.; SOBRINO, J. (Ed.) Mysterium Liberationis. Fundamental Concepts of Liberation Theology. Maryknoll; NY: Orbis Books, 1993. p. 251. 
Enquanto a necessidade da acolhida de imigrantes e refugiados emerge socialmente e desafia, de modo particular, atores e contextos eclesiais, o imperativo da intercultura se abre ao horizonte como única possibilidade de futuro para a convivência entre povos que se encontram e desencontram por causa dos movimentos populacionais.

A interculturalidade, desse modo, se torna chave hermenêutica para uma abordagem aberta e complexa às migrações internacionais. A intercultura se propõe a gerar diferentes processos dialogais e interativos, por uma variedade de mundos e de qualidades em relações inclusivas, capazes de interromper as correntes maléficas que surgem e se impõem no mundo contemporâneo, pois a lógica intercultural não tem medo de produzir um pensamento que edifica, que tem metas e declinações pragmáticas. A interculturalidade é um modo de se situar e de se posicionar que favorece processos e posturas sustentáveis para todos/as os/as atores.

Trata-se de uma opção, de mentalidade, escolhas estratégicas, investimento de tempo, poder e recursos com ou sem pessoas em processos de vulnerabilidade, de alteridade e de criatividade que fazem irrupção na imprevisibilidade dos processos existenciais e históricos, como as migrações e outros fenômenos humanos, que acontecem e podem ser levados a sério como kairós. Mas estas oportunidades, contrariamente, podem ser perdidas por opções que fortalecem as barreiras da segurança de poucos e preferem a homogeneização que quer todos e todas moldurados nos parâmetros e significados que traduzem padrões de comportamento regidos pela aparência e a esterilidade. Com Panikkar consideramos que a intercultura é pensamento em ação, é filosofia, pensamento com comprometimento por um mundo melhor.

\section{Considerações finais}

A constatação da chegada ou da presença de imigrantes internacionais em contextos novos, institucionais, sociais ou eclesiais, pode fazer surgir atores visíveis e invisíveis que querem marcar território, favorecendo tensões nas relações. Ou podem romper esquemas e desencadear processos regeneradores de vida nova, de fé e de diálogo intercultural.

A irrupção de migrantes ou refugiados num contexto local mobiliza oportunidades e recursos, inclusive nas comunidades eclesiais, e tal dinamismo pode favorecer o surgimento ou a intensificação de inimizades. Esse tipo de reação se explica pelo interesse de apropriar-se das oportunidades que a ocasião favorece, pela "síndrome da ideologia da cultura superior" (PANIKKAR, 2006, p. 106), que marca o tratamento que sociedades e igrejas atribuem à temática migratória e seus atores. Em posições existenciais e 
ideologicamente diferentes, outras reações podem acontecer e, sobretudo, podem ser favorecidas por processos interativos de migrantes, de refugiados e de comunidades cristãs interculturais.

A alteridade que migrantes e refugiados representam expõe o modo como as diferenças são interpretadas e, consequentemente, como os recursos e as oportunidades são repartidos e apropriados. A alteridade que as migrações internacionais aguçam nos contextos locais e nacionais pode ser fermento para a solidariedade entre pobres e excluídos, entre sujeitos e comunidades, inclusive autóctones, ou pode, contrariamente, intensificar conflitos e preconceitos, na Igreja como na sociedade em geral. Segundo Panikkar, a lógica do amor e da fé determinam intrinsecamente processos interculturais.

Conforme argumentado no decorrer do texto, Panikkar ensina que "a interculturalidade nos revela nossos limites, nos ensina a tolerância e nos faz compreender a contingência da condição humana" (2006, p. 71). Ao mesmo tempo, do pensador indo-espanhol aprendemos que a intercultura também nos empodera para contribuir na construção de um mundo diferente do que vivemos hoje. Ele explica que a desconfiança no outro levou à perda da confiança em nós mesmos, pois a desconfiança é mútua e contagiosa, e isso impede radicalmente as relações interculturais. Sem uma abordagem intercultural, as pessoas priorizam a segurança; essa "se encontra na força (política, física, econômica, militar...), a certeza em uma necessidade epistemológica, a confiança na natureza humana. A busca da primeira é motivada pelos nossos temores, a segunda pelas nossas dúvidas e a terceira pela nossa fé" (PANIKKAR, 2006, p. 1105-106). Por isso, o desafio pastoral que a interculturalidade determina está fundamentalmente na qualidade das relações interpessoais dos crentes, pois a confiança é seu eixo estruturante.

Algumas pistas pastorais se abrem a partir dessa compreensão da interculturalidade e da configuração que a abordagem intercultural favorece nas relações interpessoais e na construção da convivência coletiva. Como intercultura não é modelo nem paradigma, as pistas pastorais recalcam as dinâmicas que fomentam e que são fomentadas pela interculturalidade. A construção de pensamento e de ações inspiradas no evangelho orientam a praxe eclesial para: a) o cuidado pela dignidade e o reconhecimento do valor imprescindível e inalienável do ser humano; b) a promoção de processos de transformação para a construção de sociedades inclusivas e a consolidação da justiça; c) a construção de metodologias e conteúdos teológicos marcados pela transformação intercultural; e, d) o compromisso individual e comunitário que expressa uma atitude interior de não conformação ao status quo da conjuntura global, enquanto acreditamos no envio missionário e operamos na construção do Reino anunciado e inaugurado na Encarnação do filho de Deus. 


\section{Referências}

ESSEN, G. Interkulturelle Theologie. In: STRAUB, J.; WEIDEMANN, A.; WEIDEMANN, D. (Hg.). Handbuch interkulturelle Kommunikation und Kompetenz: Grundbegriffe - Theorien - Anwendungsfelder. Stuttgart: J. B. Metzler, 2007.

ELLACURÍA, I.; SOBRINO, J. (Ed.) Mysterium Liberationis. Fundamental Concepts of Liberation Theology. Maryknoll; NY: Orbis Books, 1993.

FORNET-BETANCOURT, R. Filosofar para nuestro tiempo en clave intercultural. Aachen: Verlag Mainz, 2004.

. El quehacer teológico en el contexto del diálogo entre las culturas en América Latina. Revista Iberoamericana de Teología, Ciudad de México, n. 4, p. 73-83, 2017.

FRANCISCO, Papa. Por una cultura del encuentro. Ciudad del Vaticano, 13/09/2016. Disponível em: <http://w2.vatican.va/content/francesco/es/cotidie/2016/documents/papa-francesco-cotidie_20160913_cultura-encuentro.html>. Acesso em: 20 fev. 2019.

GMAINER-PRANZL, F. Teologia intercultural: a forma discursiva da catolicidade. Protestantismo em Revista, São Leopoldo, v. 28, p. XXX, Maio/Ago. 2012.

LAGARDE Y DE LOS RÍOS, M. El feminismo en mi vida. Hitos, claves y utopías. México: Instituto de las Mujeres del Distrito Federal, 2012.

LUSSI, C. Migrações e alteridade na comunidade cristã. Ensaio de teologia da mobilidade humana. Brasília: CSEM, 2015.

MASSEY, D. S. Comprender las migraciones internacionales. Teorias, prácticas y politicas migratorias. Barcelona: Bellatterra, 2017.

MARINUCCI, R. Mulheres, migrantes e muçulmanas. Percursos de discriminação e empoderamento. In: NOGALES VASCONSELOS, A. M.; BOTEGA, T. (Orgs.). Política migratória e os paradoxos da globalização. Porto Alegre: EdiPUCRS; Brasília: CSEM, 2015. p. 189-207.

NARAYAH, Uma. Dislocating Cultures: Identities, Traditions, and Third World Feminism. New York; London: Routledge, 1997.

PANIKKAR, R. Pace e interculturalità. Una riflessione filosofica. Milano: Jaca Book, 2006.

Pluralismo e interculturalità. Culture e religioni in dialogo. Milano: Jaca Book, 2009. t. 1.

PILAR AQUINO, M. Feminist Intercultural Theology. Toward a Shared Future of Justice. In: PILAR AQUINO, M; ROSADO-NUNES, M. J. Feminist Intercultural Theology: Latina explorations for a just world. San Diego: Orbis Books, 2007. p. 9-28.

SKODA, A. Per una teoria della prassi nella pastorale della mobilità umana. Modelli di pastorale delle migrazioni e della mobilità. Disponível em: <https://www.diocesitv. 
it/pastorale-migrazioni/wp-content/uploads/sites/9/2017/10/Migrazioni-e-sfide-socio-pastorali.pdf>. Acesso em: 02 mar. 2019.

TOLEDO DE SOUZA, F. O êxodo dos refugiados e o direito a resistir. Revista Direito e Práxis, Rio de Janeiro, v. 5, n. 9, p. 101-117, 2014.

VON SINNER, R. O cristianismo a caminho do Sul: teologia intercultural como desafio à teologia sistemática. Estudos Teológicos, v. 52, n. 1, p. 38-62, 2012.

ZANFRINI, L. Sociologia delle differenze e delle disuguaglianze. Bologna: Zanichelli, 2011.

Artigo submetido em 14.03.2019 e aprovado em 15.07.2019.

Carmem Lussi é doutora em Teologia pela Pontifícia Universidade Católica do Rio de Janeiro - PUC-RIO (2013), mestra em Missiologia pela Pontifícia Universidade Urbaniana (2002). Assessora do Centro Scalabriniano de Estudos Migratórios (CSEM). Orcid.org/00000002-5666-7870. E-mail: carmem.lussi@gmail.com

Endereço: SRTVN $702 \mathrm{Cj}, \mathrm{P}$

Ed. Brasília Radio Center Sobrelojas 1 e 2

70719-900 - Brasília DF 